\title{
Anesthesia for liver transplantation from a maastricht category 4 non-heart-beating donor -A case report-
}

\author{
Sue Kyung $\mathrm{Yu}^{1}$, Gaab Soo Kim ${ }^{1}$, and Jun Young Chung ${ }^{2}$ \\ Department of Anesthesiology and Pain Medicine, 'Samsung Medical Center, Sungkyunkwan University School of Medicine, \\ ${ }^{2}$ East-West Neo Medical Center, Kyung Hee University School of Medicine, Seoul, Korea
}

Great improvements in patient selection, surgical techniques, perioperative care, and immunosuppression have been made for the optimization of liver transplantation. To increase the number of organs available for liver transplantation, transplant centers have used marginal donors, split livers, living donors, or non-heart-beating donors (NHBDs). Despite recent enthusiasm for NHBDs in liver transplantation, warm ischemic injury to recovered organs has been an obstacle for the wide acceptance of NHBD. In the present case, we have conducted a liver transplantation from a Maastricht Category 4 NHBD. Warm ischemic time was 20 minutes and cold ischemic time was 5 hour 43 minutes. Consequently, the liver was successfully transplanted into the recipient. (Korean J Anesthesiol 2010; 59: S119-S123)

Key Words: Liver transplantation, Maastricht criteria, Non-heart-beating donor (NHBD), Warm ischemic time (WIT).

Since the inception of liver transplantation, multiple methods such as split liver transplantation from brain death donors, liver transplantation from living donors and marginal donors [1] have been employed to expand the pool of liver donors which are in short supply, to address the increasing demand of recipients. Among the marginal donors, a non-heart-beating donor (NHBD) refers to an individual for whom cardiac death has been pronounced accompanied with nerve damage, while heart-beating donor (HBD) refers to individuals who have been declared as brain dead.

We performed anesthesia for liver transplantation on a nonheart-beating donor (NHBD) whose organ was removed by the waiting surgical team when the donor in brain death underwent cardiac arrest in the operating room. We report the experience of liver transplantation anesthesia with a review of the relevant literature.

\section{Case Report}

A 49-year-old, $70 \mathrm{~kg}, 175 \mathrm{~cm}$ tall male donor was admitted to the operating room (OR) at 21:20 for organ donation after he was declared brain dead due to hypoxic brain injury. Ventilation was performed with a tidal volume of $450 \mathrm{ml}$, tidal rate of $30 / \mathrm{min}$ and positive-end expiratory pressure (PEEP)

Received: September 1, 2009. Revised: 1st, September 11, 2009; 2nd, September 18, 2009. Accepted: September 24, 2009.

Corresponding author: Gaab Soo Kim, M.D., Department of Anesthesiology and Pain Medicine, Samsung Medical Center, Sungkyunkwan University School of Medicine, Irwon-dong, Gangnam-gu, Seoul 135-710, Korea. Tel: 82-2-3410-0360, Fax: 82-2-3410-0361, E-mail: gskim@skku.edu (c) This is an open-access article distributed under the terms of the Creative Commons Attribution Non-Commercial License (http:// creativecommons.org/licenses/by-nc/3.0/), which permits unrestricted non-commercial use, distribution, and reproduction in any medium, provided the original work is properly cited. 
of $5 \mathrm{cmH}_{2} \mathrm{O}$. Norepinephrine $1.5 \mu \mathrm{g} / \mathrm{kg} / \mathrm{min}$, vasopressin 2.4 $\mathrm{U} / \mathrm{hr}$, dopamine $30.4 \mu \mathrm{g} / \mathrm{kg} / \mathrm{min}$, and dobutamine $57 \mu \mathrm{g} / \mathrm{kg} /$ min were initially provided at the intensive care unit (ICU) and continuously administered. On admission, measurement taken at the radial artery showed blood pressure (BP) of 86/56 $\mathrm{mmHg}$, central venous pressure (CVP) of $16-17 \mathrm{mmHg}$, cardiac rate of $120 / \mathrm{min}$, oxygen saturation $\left(\mathrm{SO}_{2}\right)$ of $93 \%$ and partial pressure of end-tidal carbon dioxide $\left(\mathrm{PETCO}_{2}\right)$ of $28 \mathrm{mmHg}$. Arterial blood gas analysis performed at 21:30 indicated a $\mathrm{pH}$ of 7.310, partial pressure (tension) of oxygen $\left(\mathrm{PO}_{2}\right)$ at $60.7 \mathrm{mmHg}$, $\mathrm{CO}_{2}$ tension at $30.4 \mathrm{mmHg}$, oxygen saturation $\left(\mathrm{SO}_{2}\right)$ of $91 \%$, bicarbonate $15.0 \mathrm{mmol} / \mathrm{L}$, base excess $-10.3 \mathrm{mmol} / \mathrm{L}, \mathrm{Na}^{+} / \mathrm{K}^{+} /$ $\mathrm{Cl}^{-}$134.1/4.4/115 mmol/L, hemoglobin at $7.8 \mathrm{~g} / \mathrm{dl}$, hematocrit (Hct) $23 \%$ and a blood glucose (sugar) level of $144 \mathrm{mg} / \mathrm{dl}$. Following measurements taken at 21:40, when BP was $45 / 32$ mmHg; CR, 112/min; $\mathrm{SO}_{2}$, 88\%; $\mathrm{PETCO}_{2}, 20 \mathrm{mmHg}$, an increase of fluid intake was established and $20 \mu \mathrm{g}$ of epinephrine was administered. Thereafter, systolic blood pressure increased to $50-60 \mathrm{mmHg}$ and the surgeon was consequently informed of the patient's critical condition, which initiated the start of the operation. Shortly in to the procedure, when pulsation of the carotid artery was palpable and weakened, $500 \mu \mathrm{g}$ of epinephrine was injected, but this administration proved to be ineffective. At 21:45, the patient displayed asystole (cardiac standstill) and 1,000 $\mu$ g of epinephrine was administered, which made no effect and cardiopulmonary resuscitation (CPR) was consequently initiated. During continuous CPR, additional administration of epinephrine at of the following doses, 1,000 $\mu \mathrm{g}, 2,000 \mu \mathrm{g}$, and 2,000 $\mu \mathrm{g}$ was given. Until the occurrence of aortic occlusion, a fluid therapy of 1,000 $\mathrm{ml}$ of crystalloid solution and 1,000 $\mathrm{ml}$ of colloid solution was delivered. The BP of the patient did not respond to the fluid therapy since it was maintained at $52-58 / 36-40 \mathrm{mmHg}, \mathrm{SO}_{2}$ at $50-70 \%$. At 22:00 when perfusion was performed simultaneously with aortic occlusion, CPR was terminated. The perfusion was completed at 22:17 and the liver was retrieved at 22:45 (Table 1).

The retrieved liver was transplanted to a male recipient in a state of hepatic coma, who was 38 years old, $75.8 \mathrm{~kg}$ in weight, $181.1 \mathrm{~cm}$ in height, and with the Model for End-Stage Liver Disease (MELD) scores of 40. While his femoral arterial and venous pressure were monitored, a 9-Fr catheter (Advanced venous access $\mathrm{HF}^{\circledR}$, Edwards Life Science Corporation, USA) and a multifunctional pulmonary artery catheter (Swan-Ganz CCOmbo CCO/SvO , Edwards Life Science Corporation, USA) were placed into the internal jugular vein. At the onset of operation, dopamine $5.0 \mu \mathrm{g} / \mathrm{kg} / \mathrm{min}$ and norepinephrine $0.05-$ $0.1 \mu \mathrm{g} / \mathrm{kg} / \mathrm{min}$ were injected. At 3 hours and 20 minutes after anesthesia induction, the patient entered the anhepatic phase, and 1 hour and 3 minutes later, reperfusion was performed. At the time of reperfusion, an abnormality appeared when the patient's BP decreased to $78 / 40 \mathrm{mmHg}$, CR to $75 / \mathrm{min}$, but the administration of epinephrine $50 \mu \mathrm{g}$ once and atropine $0.5 \mathrm{mg}$ twice restored these to normal states. Intra-operative BP, except for the reperfusion period, was maintained at a relatively stable state of BP between 95-130 and 44-70 mmHg, CR between $75 / \mathrm{min}$ and $98 / \mathrm{min}$ (Table 2). After the liver transplantation, which lasted 7 hours-and-50 minutes, was completed, the patient's vital signs indicated BP 109/59 $\mathrm{mmHg}$, CR 86/min, and $\mathrm{SO}_{2} 100 \%$. He was then transferred to the intensive care unit (ICU), when dopamine $5.0 \mu \mathrm{g} / \mathrm{kg} / \mathrm{min}$ and norepinephrine 0.3 $\mu \mathrm{g} / \mathrm{kg} / \mathrm{min}$ were administered as vasopressor. All of the intraoperative intakes of fluid and blood products included 4,900 $\mathrm{ml}$ of crystalloid solution, $880 \mathrm{ml}$ of $5 \%$ glucose solution, 1,500 $\mathrm{ml}$ of colloid solution, 1 unit of packed leukocyte-depleted red blood cells (RBC), 4 units of fresh frozen plasma (FFP), 6 units of cryoprecipitates, $500 \mathrm{ml}$ of $5 \%$ albumin, and 1,108 ml of retrieved blood by cell saver, while the urine output was 115 $\mathrm{ml}$; ascites, 3,000 ml; blood loss, 2,000 ml. On postoperative day 3 , the patient occasionally displayed convulsive motions, but was able to respond to instructions. On postoperative day 6 , the endotracheal tube was removed, and on postoperative day 12 he was transferred to the general ward. On postoperative day 61 , he was finally discharged home.

\section{Discussion}

Brain dead patients undergo deterioration of the metabolic function of other organs before determination of brain death and $80 \%$ of them incur cardiac death within 120 hours because cardiopulmonary function is degenerated despite active treat-

Table 1. Vital Signs and Events during Liver Extraction from NHBD

\begin{tabular}{|c|c|c|c|c|c|c|c|c|c|}
\hline & $21: 20$ & $21: 25$ & $21: 30$ & $21: 35$ & $21: 40$ & $21: 45$ & $22: 00$ & $22: 17$ & $22: 45$ \\
\hline $\mathrm{BP}(\mathrm{S} / \mathrm{D})(\mathrm{mmHg})$ & $86 / 56$ & $92 / 54$ & $130 / 74$ & $102 / 64$ & $45 / 32$ & Asystole & perfusion start & perfusion finish & Liver harvest \\
\hline $\operatorname{HR}(/ \min )$ & 120 & 124 & 126 & 120 & 112 & - & - & - & - \\
\hline $\mathrm{SpO}_{2}(\%)$ & 93 & 95 & 96 & 99 & 88 & - & - & - & - \\
\hline $\mathrm{ET}_{\mathrm{CO} 2}(\mathrm{mmHg})$ & 28 & 30 & 30 & 25 & 20 & - & - & - & - \\
\hline Events & & & ABGA & & EPI $20 \mu \mathrm{g}$ & CPR start & CPR finish & & \\
\hline
\end{tabular}

$\overline{\mathrm{BP}}$ (S/D): blood pressure (systolic/diastolic), HR: heart rate, $\mathrm{SpO}_{2}: \mathrm{O}_{2}$ Saturation, $\mathrm{ET}_{\mathrm{CO} 2}$ : end tidal $\mathrm{CO}_{2}$, ABGA: arterial blood gas analysis, EPI: epinephrine, CPR: cardio-pulmonary resuscitation. 
Table 2. Hemodynamic Datas and Laboratory Results during Liver Transplatation

\begin{tabular}{|c|c|c|c|c|c|c|c|c|c|c|c|}
\hline Time & & Pre-op & $I+60^{\prime}$ & $\mathrm{I}+120^{\prime}$ & $\mathrm{I}+180^{\prime}$ & $\mathrm{II}+60^{\prime}$ & $\mathrm{III}+5^{\prime}$ & $\mathrm{III}+30^{\prime}$ & $\mathrm{III}+60^{\prime}$ & $\mathrm{III}+120^{\prime}$ & $\begin{array}{l}\text { ICU } \\
\text { arrival }\end{array}$ \\
\hline \multirow{5}{*}{$\begin{array}{l}\text { Hemo- } \\
\text { dynamics }\end{array}$} & HR (rate/min) & 65 & 78 & 80 & 78 & 74 & 75 & 86 & 87 & 83 & 86 \\
\hline & $\begin{array}{l}\mathrm{BP}(\mathrm{S} / \mathrm{D}(\mathrm{M})) \\
(\mathrm{mmHg})\end{array}$ & $\begin{array}{c}115 / 68 \\
(-)\end{array}$ & $\begin{array}{c}116 / 60 \\
(82)\end{array}$ & $\begin{array}{c}128 / 69 \\
(91)\end{array}$ & $\begin{array}{c}125 / 64 \\
(86)\end{array}$ & $\begin{array}{c}96 / 51 \\
(68)\end{array}$ & $\begin{array}{c}91 / 44 \\
(62)\end{array}$ & $\begin{array}{c}115 / 55 \\
(77)\end{array}$ & $\begin{array}{l}101 / 46 \\
(66)\end{array}$ & $\begin{array}{c}113 / 51 \\
(73)\end{array}$ & $\begin{array}{c}109 / 59 \\
(-)\end{array}$ \\
\hline & $\begin{array}{l}\text { CVP/FVP } \\
\text { (mmHg, mmHg) }\end{array}$ & - & $15 / 17$ & $12 / 19$ & $9 / 17$ & $9 / 14$ & $10 / 14$ & $12 / 14$ & $8 / 14$ & $10 / 13$ & - \\
\hline & $\begin{array}{l}\text { PCWP/EDV } \\
\text { (mmHg,ml) }\end{array}$ & - & $22 / 310$ & $16 / 276$ & $11 / 224$ & $11 / 316$ & $18 / 317$ & $16 / 303$ & $10 / 240$ & $17 / 265$ & - \\
\hline & $\begin{array}{l}\text { CO/ RVEF } \\
(\mathrm{L} / \mathrm{min}, \%)\end{array}$ & - & $10.7 / 45$ & $9.5 / 45$ & $9.0 / 52$ & $12.6 / 52$ & $12.3 / 51$ & $13.2 / 52$ & $10.2 / 50$ & $10.6 / 47$ & - \\
\hline \multirow[t]{5}{*}{ ABGA } & $\mathrm{pH}$ & 7.54 & 7.42 & 7.43 & 7.43 & 7.51 & 7.42 & 7.45 & 7.41 & 7.35 & 7.38 \\
\hline & $\mathrm{PaCO}_{2}(\mathrm{mmHg})$ & 35 & 45 & 42 & 40 & 31 & 36 & 34 & 36 & 44 & 40.7 \\
\hline & $\mathrm{PaO}_{2}(\mathrm{mmHg})$ & 82 & 166 & 134 & 126 & 168 & 311 & 108 & 161 & 97 & 98.7 \\
\hline & $\mathrm{HCO}_{3}{ }^{-}(\mathrm{mmol} / \mathrm{L})$ & 30 & 29 & 27 & 26 & 25 & 23 & 23 & 23 & 24 & 23.5 \\
\hline & $\mathrm{BE}(\mathrm{mmol} / \mathrm{L})$ & - & 4.4 & 3.2 & 2.2 & 2.1 & -0.4 & 0.0 & -1.3 & -1.6 & -1.5 \\
\hline \multirow[t]{5}{*}{ Electrolytes } & $\mathrm{Na}^{+}(\mathrm{mmol} / \mathrm{L})$ & 142 & 141 & 141 & 140 & 138 & 137 & 139 & 138 & 139 & 139 \\
\hline & $\mathrm{K}^{+}(\mathrm{mmol} / \mathrm{L})$ & 4.0 & 3.6 & 3.8 & 3.8 & 3.8 & 3.9 & 3.9 & 4.1 & 4.3 & 4.6 \\
\hline & $\mathrm{Ca}^{2+}(\mathrm{mmol} / \mathrm{L})$ & 1.2 & 1.2 & 1.1 & 1.0 & 1.0 & 1.0 & 1.0 & 1.0 & 1.1 & 1.1 \\
\hline & Glu (mg/dl) & 120 & 96 & 90 & 94 & 103 & 119 & 117 & 120 & 110 & 113 \\
\hline & Lactate $(\mathrm{mmol} / \mathrm{L})$ & 1.7 & 1.4 & 1.5 & 1.7 & 2.1 & 3.6 & 3.2 & 3.1 & 2.7 & - \\
\hline \multirow[t]{2}{*}{ Hematology } & $\mathrm{Hb}(\mathrm{g} / \mathrm{dl})$ & 7.7 & 9.6 & 9.8 & 8.8 & 7.0 & 6.8 & 7.8 & 8.2 & 9.3 & 9.3 \\
\hline & Hct $(\%)$ & 25.1 & 31.2 & 29 & 28.5 & 22.9 & 22.0 & 23 & 26.3 & 27 & 30.3 \\
\hline \multirow[t]{5}{*}{ Coagulation } & Platelets $(1,000 / \mu \mathrm{l})$ & $71 \mathrm{~K}$ & $55 \mathrm{~K}$ & - & $52 \mathrm{~K}$ & $43 \mathrm{~K}$ & $46 \mathrm{~K}$ & - & $46 \mathrm{~K}$ & - & $43 \mathrm{~K}$ \\
\hline & PT (INR) & 4.77 & 6.15 & - & 4.46 & 6.19 & 7.08 & - & 3.90 & - & 2.81 \\
\hline & aPTT (sec) & 62.1 & 70.3 & - & 83.5 & 92.3 & 96.1 & - & 98.8 & - & 62.7 \\
\hline & ACT (sec) & - & 201 & & - & - & 203 & & 215 & & - \\
\hline & Fibrinogen $(\mathrm{mg} / \mathrm{dl})$ & 120 & 115 & - & 109 & 73 & 58 & - & 62 & - & 123 \\
\hline
\end{tabular}

Pre-op: pre-operation, I: preanhepatic period, II: anhepatic period, III: post-reperfusion period, ICU: intensive care unit, ABGA: arterial blood gas analysis, PT: prothrombin time, INR: international normalized ratio, aPTT: actvated partial thromboplastin time, ACT: activated clotting time, CVP: central venous pressure, FVP: femoral vein pressure, PCWP: pulmonary capillary wedge pressure, EDV: end diastolic volume, CO: cardiac output, RVEF: right ventricle ejection fraction.

ments [2]. Metabolic disorder and hematologic deterioration causes cardiac arrest. Therefore, the most important goal of managing deceased organ donors is to maintain hematologic stability and physiological balance. Hypovolemia, hypothermia, endogenous hormonal changes, left ventricular failure and other similar conditions cause hypotension for a majority of brain dead individuals, which contributes to cardiac output decrease, myocardial impairment, decrease of afterload and other similar symptoms. To confront hypotension, fluid administration of crystalloid and colloid solutions or blood transfusion is performed to correct hypovolemia and increase urine output. If low blood pressure sustains even after hypovolemia is corrected, dopamine should be administered primarily and other drugs such as norepinephrine, epinephrine, vasopressin and dobutamine also should be used to maintain BP within the normal ranges. The guidelines of anesthesia management for brain dead people published in 1990 states the maintenance of systolic blood pressure $>100 \mathrm{mmHg}$ (median BP 70-110 mmHg), arterial oxygen tension $\left(\mathrm{PaO}_{2}\right)>100$ $\mathrm{mmHg}$, urine output $>100 \mathrm{ml} / \mathrm{hr}(1-1.5 \mathrm{ml} / \mathrm{kg} / \mathrm{hr})$, hemoglobin $>10 \mathrm{~g} / \mathrm{dl}$, and central venous pressure (CVP) at 5-10 $\mathrm{mmHg}$ [3]. Since lung transplantation teams favor a low CVP, while liver transplantation teams prefer a high CVP, it is important to maintain a proper CVP for the different types of donated organs. As for liver transplantation, maintenance of CVP under 10 $\mathrm{mmHg}$ is recommended due to the effects of hepatic edema on transplantation. During bradycardia in brain dead individuals, atropine does not result in significant responses, therefore the use of direct-acting chronotropic drugs such as isoproterenol and epinephrine is required and CPR should be ready to apply to address incidences of cardiopulmonary arrest.

For heart-beating donors (HBD), warm ischemic injury, which occurs between cardiac arrest and the onset of organ perfusion, is adequate because ventilation and pulsation is applied immediately prior to the organ removal [4]. For non-heartbeating donors (NHBD), where the retrieval of organs follows cardiac death, the degree of warm ischemic injury varies between organs, therefore postoperative results of liver transplants fluctuate, leaving the patient vulnerable to delayed primary graft nonfunctioning or complete graft nonfunctioning [4].

Non-heart-beating donors (NHBD), who are declared dead due to cardiopulmonary function effacement have been classified into 4 categories according to the Maastricht criteria determined at the Maastricht Workshop in 1994 [5]. In the 
division of uncontrolled NHBD, including category 1 and 2, category 1 refers to 'dead on arrival' whereas category 2 refers to death due to unsuccessful cardiopulmonary resuscitation (CPR). On the other hand, in the division of controlled NHBD, including category 3 and 4, category 3 means the status of readiness of organ retrieval from a donor who is brain dead and whose life support system is withdrawn with consent by the patient's next of kin for organ donation. Immediately after cardiopulmonary function ceases when the administration of medicine and respirator aid to the donor are terminated, the waiting surgical team recovers the organs. Category 4 refers to cardiac arrest occurring to a brain dead donor [5]. Therefore, the majority of organ transplantation centers prefer controlled NHBD, so donors of category 3 constitute the majority of NHBDs. The NHBD in the present case belongs to category 4 .

Transplantation form NHBDs is growing in importance as a promising means to increase the number of organ donors from approximately $10 \%$ up to $20 \%$ or higher [4]. As for renal transplantation from NHBDs, dysfunction of an implanted kidney does not present a serious problem because kidney dialysis can be employed as an auxiliary method. Liver transplantation form NHBDs, however, is highly susceptible to complications of the vascular and biliary systems, which potentiates the risk of surgery as the most effective alternative. According to Foley at al., the incidence of hepatic artery thrombosis reached $16.6 \%$ while the incidence of biliary stenosis came to $13.8 \%$ [6]. Maheshwari et al. [7] reported that the incidence of ischemic type biliary lesion rose to $50 \%$. Early data from Casavilla et al. [8] showed the 1-year graft survival rate was $20 \%$, while recent data released by American United Network of Organ Sharing revealed that the 3-year survival rate was $63 \%$, which is a remarkable improvement, comparable with $72 \%$ survival rate of HBD. In England, where NHBDs constitute 14 $\%$ of the total transplantations, 1-year graft survival rates from NHBDs have been reported to amount to $80 \%$ [9].

Even though there have been many reports on increases in organ graft survival from NHBDs, there is still concern about organ graft nonfunctioning, primarily because warm ischemic injury was inevitable due to hypotension and circulatory arrest after the cessation of cardiac pulsation. In order to increase graft survival rate, warm ischemic time (WIT) should be within 30 minutes while donor age should be $\leq 40$ years and cold ischemic time (CIT) should be $<8$ hours $[9,10]$. A study reported that engraftment failure rate increased to $60 \%$ in the case of CIT $>12$ hours while the engraftment failure rate decreased to $10 \%$ or below in the case of CIT $\leq 8$ hours [11].

According to a report by Monbaliu et al. [12] in 2007, between January $1^{\text {st }}, 2003$ and November $30^{\text {th }}, 2005,16$ of 642 liver transplantations from brain dead people (2.45\%) were performed from NHBD, one case among which was Maastricht category-4 NHBD. They defined warm ischemic time (WIT) as the time between ventilator switch-off time and the onset of organ perfusion, and thus comparing WIT $<30$ minutes and WIT $>30$ minutes, they reported that the incidence of biliary complications in case of WIT $>30$ minutes was $37.5 \%$ higher than in case of WIT $<30$ minutes. Many agree that it is ideal to keep WIT to less than 30 minutes [13], but the definition of WIT differs from transplant center to center. Some transplant centers have defined WIT as the time between the start of decrease in systolic arterial pressure and the onset of organ perfusion [14]. What is noteworthy in the episode experienced by Monbaliu et al. [12] where even though primary graft nonfunctioning did not develop in liver transplantation from Maastricht category-4 NHBDs, malfunction of the graft was detected immediately after liver transplantation and hepatic artery thrombosis occurred, with WIT of 50 minutes. If WIT is regarded as the ischemic injury time due to hypotension and circulatory arrest following the cessation of cardiac pulsation, WIT can be defined as the time between systolic arterial pressure decrease to 50 mmHg or below and the start of organ perfusion. Based on this, if time is measured from the moment of systolic arterial pressure decrease to $50 \mathrm{mmHg}$ or below, WIT in the our case is 20 minutes and does not exceed 25 minutes, even considering that a decrease in BP starts beforehand. In addition, CIT in the present case was 5 hours and 43 minutes. In retrospect, we had positive results due to the short periods of WIT and CIT.

To reduce warm ischemic periods (WIT) in NHBDs, there have been a variety of attempts made such as cardiopulmonary bypass (CPB), extracorporeal membrane oxygenation, and surgically, super rapid retrieval as a modification of the en bloc multiorgan harvest technique [8]. Simultaneously, to increase graft survival rate in recipients, it is critical to avoid prolonged surgical periods of dissection and excision, to keep vital signs within the stable ranges, and to maintain the vitality of organs [15]. It should also be taken into consideration that a prolonged WIT would aggravate a coagulation defect after reperfusion and cause acid-base imbalance.

Utilization of non-heart-beating donors (NHBDs) for the potential pool of organ donors requires organizing teams of seasoned surgeons and anesthesiologists, a change toward enhanced public awareness and acceptance of donating organs, and the legal and institutional framework for support at government level. Such efforts to increase the number of NHBDs are expected to expand the potential pool by up to $30-40 \%$ in the near future [15]. With improvements in immunosuppression and preservation of organs, and establishment of standardized surgical skills for transplantation, NHBDs will contribute to expanding the donor pool and will supplement the donor pool by $20 \%$, even though NHBD cannot replace HBD [15]. Also, future endeavors to manipulate 
ischemic injury and to access engraftment will bring benefits for expanding the pool of organ donors by NHBD. Considering the current trend toward NHBD, we tried to refine the notion of NHBD using experiences of anesthesia for non-heart-beating donors and liver transplantation. We hope that this study will help many centers expand the criteria of the donor pool, henceforth.

\section{References}

1. Busuttil RW, Tanaka K. The utility of marginal donors in liver transplantation. Liver Transpl 2003; 9: 651-63.

2. Mackersie RC, Bronsther OL, Shackford SR. Organ procurement in patients with fatal head injuries. The fate of the potential donor. Ann Surg 1991; 213: 143-50.

3. Gelb AW, Robertson KM. Anaesthetic management of the brain dead for organ donation. Can J Anaesth 1990; 37: 806-12.

4. White SA, Prasad KR. Liver transplantation from non-heart beating donors. BMJ 2006; 332: 376-7.

5. Rela M, Jassem W. Transplantation from non-heart-beating donors. Transplant Proc 2007; 39: 726-7.

6. Foley DP, Fernandez LA, Leverson G, Chin LT, Krieger N, Cooper JT, et al. Donation after cardiac death: the University of Wisconsin experience with liver transplantation. Ann Surg 2005; 242: 724-31.

7. Maheshwari A, Maley W, Li Z, Thuluvath PJ. Biliary complications and outcomes of liver transplantation from donors after cardiac death. Liver Transpl 2007; 13: 1645-53.

8. Casavilla A, Ramirez C, Shapiro R, Nghiem D, Miracle K, Bronsther $\mathrm{O}$, et al. Experience with liver and kidney allografts from non heart beating donors. Transplantation 1995; 59: 197-203.

9. Abt PL, Desai NM, Crawford MD, Forman LM, Markmann JW, Olthoff KM, et al. Survival following liver transplantation from non heart beating donors. Ann Surg 2004; 239: 87-92.

10. Attia M, Silva MA, Mirza DF. The marginal liver donor-an update. Transpl Int 2008; 21: 713-24.

11. D'Alessandro AM, Fernandez LA, Chin LT, Shames BD, Turgeon NA, Scott DL, et al. Donation after cardiac death: the University of Wisconsin experience. Ann Transplant 2004; 9: 68-71.

12. Monbaliu D, Van Gelder F, Troisi R, de Hemptinne B, Lerut J, Reding R, et al. Liver transplantation using non-heart-beating donors: Belgian experience. Transplant Proc 2007; 39: 1481-4.

13. Bernat JL, D'Alessandro AM, Port FK, Bleck TP, Heard SO, Medina J, et al. Report of a National Conference on Donation After Cardiac Death. Am J Transplant 2006; 6: 281-91.

14. Muiesan P, Jassem W, Girlanda R, Steinberg R, Vilca-Melendez H, Mieli-Vergani G, et al. Segmental liver transplantation from nonheart-beating donors-an early experience with implications for the future. Am J Transplant 2006; 6: 1012- 6.

15. Deshpande R, Heaton N. Can non-heart-beating donors replace cadaveric heart-beating liver donors? J Hepatol 2006; 45: 499-503. 